\title{
Statistical approach for analyzing the transient reliability of boiler system using CAS Mathematica
}

\author{
Yakshi Bahl $^{\mathrm{a}}$, Tarun Kumar Garg ${ }^{\mathrm{b} *}$ \\ a, batyawati College, University of Delhi, Delhi INDIA \\ *Correspondence: tkgarg@ satyawati.du.ac.in
}

\begin{abstract}
The focal point of this manuscript is to address the reliability analysis of Boiler unit in the Thermal power plant driven from coal. It is made up of six subunits laid out in series and parallel manner, alongwith some standby units. The system under consideration is modelled in transient state aided by Markov birth-death process and CAS Mathematica is deployed to solve the resulting complicated system of probabilistic equations arising out of 8 working states.
\end{abstract}

KEYWORDS: Transient reliability, Boiler system, Markov process

\section{INTRODUCTION}

Power sector is one of the major role criteria to measure the country's socio-economic broadening. Over the years we have seen a tremendous hike in demand for thermal power generation and coal has emerged as an utmost vital and extensively used fuel for the purpose. The foremost basic principle used in generating Thermal Power is the conversion of heat energy arising out of steam power into electricity, by flowing the steam through generator activated turbines. These steam turbines require high pressure and high temperature entering steam. High energy being absorbed by the turbine results in dropped pressure and temperature at the exit. In order to increase the capacity of plant, different stages of steam turbines are employed such as high pressure turbine, intermediate pressure turbine and low pressure turbines. However, to increase the efficiency and minimise the wastage of resources, we device a model to reuse the resulting low pressure and low temperature steam by restoring its original vitals and then repeat the process. To restore high pressure, first convert the steam into liquid and elevate its pressure with the help of condenser heat exchangers. However temperature is increased with the aid of "water tube boiler" steered by burning pulverized coal. Initially the feed water will pass through an economizer, encapsulate energy from the flue gas and later transform into steam. The pure steam is separated at a steam drum. Finally, the resulting steam in its original state with high pressure and high temperature can be fed back into the steam turbine and the cycle can be repeated over and over again for continuous power production. However, we add super heater to extend the efficiency of a plant as we know that the higher the temperature of the steam the more efficient the cycle resulting high power output, of course taking into account the cut-off temperature that a turbine material can withhold. The heart of the plant undoubtedly lies in the Boiler unit, consummating this whole cycle. We focus in analyzing the transient state reliability of the Boiler unit system in the Thermal power plant (Jagtap, Bewoor, and Kumar, 2020), in which availability of boiler-furnace system is optimized in a steady state, using particle swarm optimization method. However, in this paper we have obtained a Markov model and studied the reliability of the above mentioned system in a time-dependent transient state. Further, worked upon by utilizing CAS Mathematica for the purpose due to its supreme proficiency in probability and statistics adaptivity that happens to be absolutely imperative to study reliability with precision.

\section{METHODOLOGY}

\subsection{THE SYSTEM UNIT}

The system is made up of six subsystems laid in series:

I. Subsystem A: It consists of one "boiler drum" unit whose failure leads to system failure.

II. Subsystem B: It consists of one "boiler tubing" unit whose failure leads to system failure. 
III. Subsystem C It consists of one "fuel firing system" unit whose failure leads to system failure.

IV. Subsystem D: It consists of one "Superheater" unit whose failure results to the system working in reduced capacity.

V. Subsystem E: It consists of one "Economizer" unit whose failure results to the system working in reduced capacity.

VI. Subsystem F: It consists of one "Reheater" unit whose failure results to the system working in reduced capacity.

\subsection{ASSUMPTIONS AND NOTATIONS}

Assumptions used in the system (Jagtap, Bewoor, and Kumar, 2020) "Notations for depicting diversified states of its subunits are as under:

A, B, C, D, E, F: Represents full capacity states of all six subsystems respectively.

a, b, c, d, e, f: Represents the failed states of A, B, C, $D, E$ and $F$ respectively.

$\overline{\mathbf{D}}, \overline{\mathbf{E}}, \overline{\mathbf{F}}$ : Represents the reduced state of D, E and F respectively.

$>\mathbf{a}_{1}, \mathbf{a}_{2}, \mathbf{a}_{3}, \mathbf{a}_{4}, \mathbf{a}_{5}, \mathbf{a}_{6}$ : Mean failure rate in A, B, C, D, E and $\mathrm{F}$ respectively

$\mathbf{b}_{\mathbf{1}}, \mathbf{b}_{\mathbf{2}}, \mathbf{b}_{\mathbf{3}}, \mathbf{b}_{\mathbf{4}}, \mathbf{b}_{\mathbf{5}}, \mathbf{b}_{\mathbf{6}}$ : Mean repair rate in A, B, C, D, $\mathrm{E}$ and $\mathrm{F}$ respectively

$\mathbf{P}_{\mathbf{i}}(\mathbf{t})$ : Probability of the system unit working in $i^{\text {th }}$ state at any time $t$.

回 /回: Derivative w.r.t time."

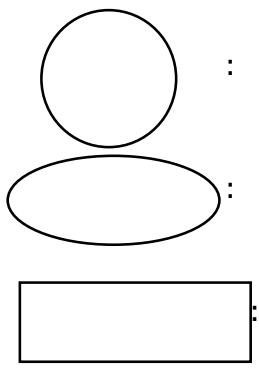

Full capacity state.

Reduced capacity state.

Failed state.

\section{SYSTEM MODELLING}

Mathematical model of Boiler System is constructed and discussed (Jagtap, Bewoor, and Kumar, 2020). The system of obtained probabilistic differential equations is solved along with the initial conditions,

$$
\begin{aligned}
{\left[\frac{d}{d t}+\sum_{\mathrm{i}=1}^{6} \mathrm{a}_{\mathrm{i}}\right] P_{0}(} & t) \\
& =b_{1} P_{41}(t)+b_{2} P_{42}(t)+b_{3} P_{43}(t) \\
& +b_{4} P_{1}(t)+b_{5} P_{2}(t) \\
& +b_{6} P_{3}(t) .
\end{aligned}
$$

$$
\begin{aligned}
{\left[\frac{d}{d t}+\sum_{\mathrm{i}=1}^{6} \mathrm{a}_{\mathrm{i}}+b_{4}\right] } & P_{1}(t) \\
= & b_{1} P_{19}(t)+b_{2} P_{20}(t)+b_{3} P_{21}(t) \\
& +b_{4} P_{22}(t)+b_{5} P_{6}(t)+b_{6} P_{4}(t) \\
& +a_{4} P_{0}(t) .
\end{aligned}
$$

$$
\begin{aligned}
{\left[\frac{d}{d t}+\sum_{\mathrm{i}=1}^{6} \mathrm{a}_{\mathrm{i}}+b_{5}\right] } & P_{2}(t) \\
= & b_{1} P_{28}(t)+b_{2} P_{29}(t)+b_{3} P_{30}(t) \\
& +b_{4} P_{6}(t)+b_{5} P_{31}(t)+b_{6} P_{5}(t) \\
& +a_{5} P_{0}(t) .
\end{aligned}
$$

$$
\begin{aligned}
{\left[\frac{d}{d t}+\sum_{\mathrm{i}=1}^{6} \mathrm{a}_{\mathrm{i}}+b_{6}\right] } & P_{3}(t) \\
= & b_{1} P_{37}(t)+b_{2} P_{38}(t)+b_{3} P_{39}(t) \\
& +b_{4} P_{4}(t)+b_{5} P_{5}(t)+b_{6} P_{40}(t) \\
& +a_{6} P_{0}(t) .
\end{aligned}
$$

$$
\begin{gathered}
{\left[\frac{d}{d t}+\sum_{\mathrm{i}=1}^{6} \mathrm{a}_{\mathrm{i}}+b_{4}+b_{6}\right] P_{4}(t)} \\
=b_{1} P_{14}(t)+b_{2} P_{15}(t)+b_{3} P_{16}(t) \\
+b_{4} P_{17}(t)+b_{5} P_{7}(t)+b_{6} P_{18}(t) \\
\quad+a_{4} P_{3}(t)+a_{6} P_{1}(t)
\end{gathered}
$$

$$
\begin{aligned}
{\left[\frac{d}{d t}+\sum_{\mathrm{i}=1}^{6} \mathrm{a}_{\mathrm{i}}+b_{4}+\right.} & \left.b_{5}\right] P_{6}(t) \\
= & b_{1} P_{23}(t)+b_{2} P_{24}(t)+b_{3} P_{25}(t) \\
& +b_{4} P_{26}(t)+b_{5} P_{27}(t)+b_{6} P_{7}(t) \\
& +a_{4} P_{2}(t)+a_{5} P_{1}(t)
\end{aligned}
$$

$$
\begin{aligned}
{\left[\frac{d}{d t}+\sum_{\mathrm{i}=1}^{6} \mathrm{a}_{\mathrm{i}}+b_{4}+\right.} & \left.b_{5}+b_{6}\right] P_{7}(t) \\
& =b_{1} P_{8}(t)+b_{2} P_{9}(t)+b_{3} P_{10}(t)+b_{4} P_{11}(t) \\
& +b_{5} P_{12}(t)+b_{6} P_{13}+a_{4} P_{5}(t) \\
& +a_{5} P_{4}(t)+\mathrm{a} P_{6}(t)
\end{aligned}
$$

$\left[\frac{d}{d t}+b_{m}\right] P_{i}(t)=a_{m} P_{j}(t)$

$m=1: \quad i=8, j=7 ; i=14, j=4 ; i=19, j=1 ; i=23, j=6$;

$\mathrm{i}=28, \mathrm{j}=2 ; \mathrm{i}=32, \mathrm{j}=5 ; \mathrm{i}=37, \mathrm{j}=3 ; \mathrm{i}=41, \mathrm{j}=0$

$m=2: \quad i=9, j=7 ; i=15, j=4 ; i=20, j=1 ; i=24, j=$

$6 ; i=29, j=2 ; i=33, j=5 ; i=38, j=3 ; i=42, j=0$.

$m=3: i=10, j=7 ; i=16, j=4 ; i=21, j=1 ; i=25, j=$

6; $i=30, j=2 ; i=34, j=5 ; i=39, j=3 ; i=43, j=0$.

$m=4: i=11, j=7 ; i=17, j=4 ; i=22, j=1 ; i=26, j=6$.

$m=5: i=12, j=7 ; i=27, j=6 ; i=31, j=2 ; i=35, j=5$

$m=6: i=13, j=7 ; i=18, j=4 ; i=36, j=5 ; i=40, j=3$ 
with the initial conditions,

$$
P_{i}(t)=\left\{\begin{array}{l}
1 \text { for } i=0 \\
0 \text { for } i \neq 0
\end{array}\right.
$$

The given system is solved under real conditions. The resulting mathematical model is solved using CAS Mathematica and the values of working states $\mathrm{P}_{0}, \mathrm{P}_{1}, \mathrm{P}_{2}$, $\mathrm{P}_{3}, \mathrm{P}_{4}, \mathrm{P}_{5}, \mathrm{P}_{6}$ and $\mathrm{P}_{7}$ at a time $\mathrm{t}$, are obtained reliability is calculated as as follows:

$$
\begin{aligned}
& \mathrm{R}_{1}(\mathrm{t})=\mathrm{P}_{0}(\mathrm{t})+\mathrm{P}_{1}(\mathrm{t})+\mathrm{P}_{2}(\mathrm{t})+\mathrm{P}_{3}(\mathrm{t})+\mathrm{P}_{4}(\mathrm{t})+\mathrm{P}_{5}(\mathrm{t})+\mathrm{P}_{6}(\mathrm{t})+ \\
& \mathrm{P}_{7}(\mathrm{t})
\end{aligned}
$$

\section{PERFORMANCE ANALYSIS OF THE SYSTEM}

We analyse the reliability with fluctuation in values of failure and repair rates.

\section{a) Variational study:}

We analyse the reliability of the system for various values of repair rates as: $b 1=0.003$,

$0.0035,0.004 \& 0.0045$ and other values of failure and repair rates as: $a_{1}=0.0004 ; a_{2}=0.0005 ; a_{3}=$ $0.0005 ; a_{4}=0.0004 ; a_{5}=0.0006 ; a_{6}=0.0004, ; b_{2}=$ $0.02 ; b_{3}=0.01$;

$b_{4}=0.005 ; b_{5}=0.005 ; b_{6}=0.004 ;$ are kept constant.

Table 1: Variation of Probability of subsystem A with respect to its repair rate with passage of time

\begin{tabular}{|c|c|c|c|c|}
\hline $\mathbf{t}$ & $\mathbf{b}_{\mathbf{1}} \mathbf{\mathbf { 0 . 0 0 3 }}$ & $\mathbf{b}_{\mathbf{1}}=\mathbf{. 0 0 3 5}$ & $\mathbf{b}_{\mathbf{1}} \mathbf{0 . 0 0 4}$ & $\mathbf{b}_{\mathbf{1}}=\mathbf{. 0 0 4 5}$ \\
\hline $\mathbf{6}$ & 0.991904 & 0.991908 & 0.991911 & 0.991915 \\
\hline $\mathbf{1 2}$ & 0.984379 & 0.984393 & 0.984407 & 0.984421 \\
\hline $\mathbf{1 8}$ & 0.97737 & 0.977401 & 0.977432 & 0.977462 \\
\hline $\mathbf{2 4}$ & 0.970831 & 0.970885 & 0.970938 & 0.97099 \\
\hline $\mathbf{3 0}$ & 0.964718 & 0.9648 & 0.964881 & 0.964962 \\
\hline $\mathbf{3 6}$ & 0.958992 & 0.959109 & 0.959223 & 0.959337 \\
\hline $\mathbf{4 2}$ & 0.95362 & 0.953776 & 0.953929 & 0.95408 \\
\hline $\mathbf{4 8}$ & 0.948571 & 0.948771 & 0.948967 & 0.94916 \\
\hline $\mathbf{5 4}$ & 0.943816 & 0.944065 & 0.944308 & 0.944548 \\
\hline $\mathbf{6 0}$ & 0.939332 & 0.939633 & 0.939928 & 0.940218 \\
\hline
\end{tabular}

b). Graphical Analysis

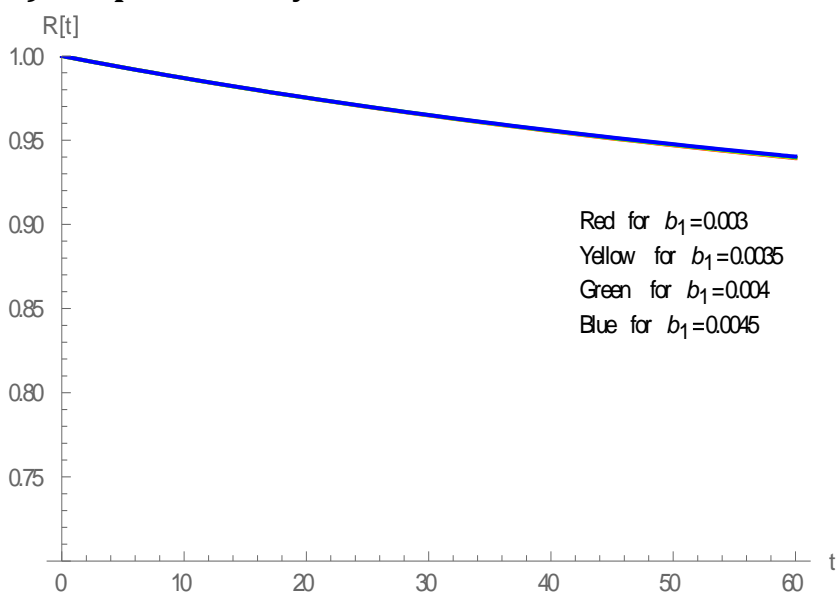

\section{CONCLUSIONS}

A study, analysing the transient reliability of boiler unit in a thermal power plant has been carried out. While performing the variational study for the boiler drum, it took cognizance of the fact that an average reliability of the system can be over $96 \%$ if we take the failure rates and repair rates in a prescribed combination. However optimum reliability reached is more than $99 \%$ and it decreases as time increases and increases with increase in repair rates. Similar analysis has been carried out for other subunits as well, concluding that the model capable of generating the average reliability exceeding $97 \%$ in transient state. Also, CAS Mathematica acted as crest in acquainting us with accurate results, that proves to be highly advantageous for the company management.

\section{REFERENCES}

Bahl, Y., Garg, T. (2021). Modified modelling and Reliability Measure of Ammonia Synthesis Unit in a Fertilizer Plant. Turkish Journal of Computer and Mathematics Education, 12(10), 2089-2196.

Cekyay, B., Ozekici, S. (2015). Reliability MTTF and steady-state availability analysis of systems with exponential lifetimes. Applied Mathematical Modelling, 39(1), 284-96.

Cekyay, B., Ozekici, S. (2015). Reliability MTTF and steady-state availability analysis of systems with exponential lifetimes. Applied Mathematical Modelling, 39(1), 284-96.

Du, S., Zeng, Z., Cui, L., Kang, R. (2017). Reliability analysis of Markov history-dependent repairable systems with neglected failures. Reliability Engineering and System Safety, Vol 159, 134-142.

Garg, S., Singh, J., Singh, D.V. (2010). Mathematical modelling and performance analysis of combed yarn production system: Based on few data. Journal of Applied Mathematical Modelling, 34 (11), 3300-08.

Garg, T. (2015). Application of CAS Maxima to the Availability Analysis of Screening Unit in a paper plant, International Journal of Computer \& Mathematical Sciences, Vol 4, Issue 6.

Jagtap, H., Bewoor, A., Kumar, A., Ahmadi, M. H. and Lorezini, G. (2020). Energy Reports 6, 1124-1134.

Jindal, S., Garg, R., and Garg, T. K. (2020). Analysis of the Reliability of theButter-Oil Processing Plant using CAS Mathematica and Maxima. IJRTE (India), 8(6), 49664972.

Khanduja, R., Tewari, P. C. and Kumar, D. (2008). Availability analysis of bleaching system of a paper plant. Journal of Industrial Engineering, 32(1), 24-29.

Khanduja, R., Tewari, P. C. and Kumar, D. (2012). Steady state behaviour and maintenance planning of bleaching system in a paper plant. International Journal of Industrial Engineering, 7(2), 39-44. 
Kumar, A., Pant, S. (2017). Availability and Cost Analysis of an Engineering System Involving Subsystems in Series Configuration. International Journal of Quality and Reliability Management, 34(6), 879-94.

Kumar, R., Sharma, A.K., Tewari, P.C. (2011). Performance modelling of furnace draft air cycle in a thermal power plant. International Journal of Engineering Science and Technology, 3(8), 67926798.

Kumar, R., Sharma, A.K., Tewari, P.C. (2012). Markov approach to evaluate the availability simulation model for power generation system in a thermal power plant. International Journal Industrial Engineering Computations, 3 (5), 743-750.

Kumar, S., Tewari, P. C. and Kumar, S. (2009). Performance evaluation and availability Analysis of ammonia synthesis unit in a fertilizer plant. Journal of Industrial Engineering International, 5(9) 17-26.

Kumar, Y., Kumar, S., R.S. (2013). A Markov model for Reliability analysis of coal handling unit of Badarpur Thermal power Plant. International Journal of Innovative Science and Research Technology, (6), 1722.

Li, L., Yan, H., Wu, X. (2012). Numerical analysis on the reliability of space tracking, telemetering and command system based on the sparse matrix storage schemes. Proceedings of ICQR2MSE; China., p. 240244.

Malik, S., Tiwari, P.C. (2018). Performance Modeling and Maintenance priorities decision for the water flow system of a coal-based thermal power plant. International Journal of Quality and Reliability Management, 35(4), 996-1010.

Mittal, P. (2019), "Impact of Auto-regressive (AR) Process in Bullwhip Analysis in a Multi-location Supply Chain Network", Journal of Business Management and Information Systems, Vol. 6 No. 1, pp. 19-26.

Pariaman, H., Garniwa, I., Surjandari, I., Sugiarto, B. (2015). Availability improvement methodology in thermal power plant. Scientific Journal of PPI-UKM, 2 (1), 43-52.

Sandler, G.H. (1993). System Reliability Engineering. Englewood Cliffs, NJ: Printice-Hall.

Shakuntla, S., Lal, A.K., Bhatia, S.S., Singh, J. (2011). Reliability analysis of polytube industry using supplementary variable technique. Applied Mathematics and Computation, 218(8), 3981-92.

Sharma, S. and Mittal, P. (2016), "Quantifying the Bullwhip in Multi-location Supply Chain Network: The Impact of Demand Forecasting", BULMIM Journal of Management and Research, Vol. 1 No. 1, p. 55.

Sharma, S.K., Sharma, D., Sharma, V. (2010). Cost analysis for a nuclear power plant with standby redundant reactor vessel. Research Journal of Mathematics and Statistics, 2(3), 91-6.
Wang, L., Yang, Q., Tian, Y. (2017). Reliability analysis of 6-component star Markov repairable system with spatial dependence. Mathematical Problems in Engineering, (3), 279-287.

Yadav, S., Chakraborty, P. and Mittal, P. (2021), "Designing Drawing Apps for Children: Artistic and Technological Factors", International Journal of Human-Computer Interaction, pp. 1-15.

Yadav, S., Chakraborty, P. and Mittal, P. (2021), "User Interface of a Drawing App for Children: Design and Effectiveness", Advances in Intelligent Systems and Computing, Vol. 1165, pp. 53-61.

Yang, J., Meng, X., Guo, W., Guan, Y., Wang, T. (2008). An N-component series repairable system with repairman doing other work and priority in repair. Journal of Modern Applied Science, 2 (6), 163-8.

Yang, T., Cui, C., Shen, Y., Lv, Y. (2016). A novel denitration cost optimisation system for power unit boilers. Applied Thermal Engineering, Vol 96, 400410.

Zheng, F., Xu, S., Li, X. (2015). Numerical solution of the steadystate probability and reliability of a repairable system with three unites. Applied Mathematics and Computation, 263, 251-67. 